\title{
A Remarkable Ligand Orientational Effect in Osmium-Atom-Induced Blue Phosphorescence
}

\author{
Jen-Kan Yu ${ }^{[a]}$ Ya-Hui Hu${ }^{[a]}$ Yi-Ming Cheng ${ }^{[a]}$ Pi-Tai Chou, $*{ }^{[a]}$ Shie-Ming Peng ${ }^{[a]}$ \\ Gene-Hsiang Lee, ${ }^{[\mathrm{a}]}$ Arthur J. Carty, ${ }^{*[b]}$ Yung-Liang Tung, ${ }^{[\mathrm{cc}]}$ Shin-Wun Lee, ${ }^{[\mathrm{c}]}$ \\ Yun Chi, ${ }^{[c]}$ and Chao-Shiuan Liu ${ }^{[\mathrm{c}]}$
}

\begin{abstract}
A new series of $\mathrm{Os}^{\mathrm{II}}$-based carbonyl complexes cis(CO),trans$\left(\mathrm{N}_{\mathrm{py}}, \mathrm{N}_{\mathrm{py}}\right), \operatorname{cis}\left(\mathrm{N}_{\mathrm{tz}}, \mathrm{N}_{\mathrm{tz}}\right)-\left[\mathrm{Os}(\mathrm{CO})_{2}(\mathrm{bptz})_{2}\right]$ (1), $\operatorname{cis}(\mathrm{CO}), \operatorname{cis}\left(\mathrm{N}_{\mathrm{py}}, \mathrm{N}_{\mathrm{py}}\right)$, $\operatorname{rans}\left(\mathrm{N}_{\mathrm{tz}}, \mathrm{N}_{\mathrm{tz}}\right)$ [Os(bptz $\left.)_{2}(\mathrm{CO})_{2}\right] \quad(2)$, and cis $(\mathrm{CO})$,$\operatorname{trans}\left(\mathrm{N}_{\mathrm{py}}, \mathrm{N}_{\mathrm{py}}\right)$, cis $\left(\mathrm{N}_{\mathrm{tz}}, \mathrm{N}_{\mathrm{tz}}\right)-\left[\mathrm{Os}(\mathrm{CO})_{2^{-}}\right.$ $\left.(\mathrm{fptz})_{2}\right](\mathbf{3})$, where bptz and fptz denote 3-tert-butyl-5-(2-pyridyl)- and 3-trifluoromethyl-5-(2-pyridyl)-1,2,4-triazolate, respectively, have been designed and synthesized in an effort to achieve high efficiency, room-temperature blue phosphorescence. Although $\mathbf{1}$ and $\mathbf{2}$ are geometric isomers, remarkably different excited-state relaxation pathways
\end{abstract}

were observed. Complex 1 exhibits strong phosphorescence in $\mathrm{CH}_{3} \mathrm{CN}$ $\left(\Phi_{\mathrm{p}} \sim 0.47\right)$ and as a single crystal at room temperature, whereas complex 2 is nearly nonemissive under similar conditions. The associated relaxation dynamics have been comprehensively investigated by spectroscopic and relaxation dynamics as well as by theoretical approaches. Our results lead us

Keywords: carbonyl ligands
osmium $\quad$ phosphorescence
pyrazole $\cdot$ pyridine $\cdot$ triazole

to the conclusion that for complex $\mathbf{2}$, the "loose bolt" effect of metal-ligand bonding interactions plays a crucial role in the fast radiationless deactivation of this type of geometrical isomer. Fine adjustment can also be achieved by functionalizing the ligands so that the electron-withdrawing nature of the $\mathrm{CF}_{3}$ group in $\mathbf{3}$ stabilizes the HOMO of the triazolate moiety, thus moving the emission further into the pure "blue" region; this results in highly efficient phosphorescence and renders 3 particularly attractive for application in blue OLED devices.

\section{Introduction}

Recently, strong phosphorescent organometallic compounds have been intensively investigated because of their potential applications in organic light-emitting devices (OLEDs), solar energy conversion, ${ }^{[1]}$ photoreduction ${ }^{[2]}$ and oxygen sensing. ${ }^{[3]}$ These materials, such as square-planar $\mathrm{d}^{8}$ complexes of $\mathrm{Pt}^{\mathrm{II}[4]}$ and $\mathrm{Au}^{\mathrm{III}[5]}$ and octahedral $\mathrm{d}^{6}$ complexes of $\mathrm{Re}^{\mathrm{I}}{ }^{[6]} \mathrm{Os}^{\mathrm{II}}{ }^{\left[{ }^{77]}\right.} \mathrm{Ir}^{\mathrm{III}},{ }^{[8]}$ and $\mathrm{Pt}^{\mathrm{IV}[9]}$ ions, commonly exhibit superior long excited-state lifetimes and high luminescence efficiencies. Spin-orbit coupling, which is enhanced by the pres-

[a] J.-K. Yu, Y.-H. Hu, Y.-M. Cheng, Prof. P.-T. Chou, S.-M. Peng, G.-H. Lee

Department of Chemistry and Instrumentation Center National Taiwan University, Taipei 106, Taiwan (ROC) E-mail: chop@ntu.edu.tw

[b] Prof. A. J. Carty

Steacie Institute for Molecular Sciences, National Research Council Ontario K1A 0R6 (Canada)

E-mail: acarty@pco-bcp.gc.ca

[c] Y.-L. Tung, S.-W. Lee, Prof. Y. Chi, Prof. C.-S. Liu

Department of Chemistry, National Tsing Hua University

Hsinchu 300, Taiwan (ROC)

E-mail: ychi@mx.nthu.edu.tw ence of heavy-metal ions incorporated at the core of these complexes, results in highly efficient intersystem crossing, as well as the breakdown of the spin-forbidden nature of phosphorescence. $^{[10]}$ In addition, the stronger ligand field strength expected for these third-row elements makes the metal-centered $\mathrm{d}-\mathrm{d}$ transitions relatively inaccessible from the lowest emitting state, so that the competing radiationless deactivation process may no longer play a crucial role in quenching the emission. ${ }^{[1]}$ As a result, much stronger roomtemperature phosphorescence is normally observed in both the liquid and solid states.

In view of their potential applications in OLED devices, efforts have been made to design and synthesize phosphorescent metal complexes that show all three primary colors in the full-color display. On the one hand, the synthesis of a variety of green-emitting complexes has been quite successful, and many exquisite results have been documented. ${ }^{[12]}$ On the other hand, despite the intrinsic obstacle of rapid nonradiative deactivation due to the smaller energy gap, ${ }^{[13]}$ redemitting phosphorescent complexes have recently become accessible through the incorporation of more rigid polyaromatic chromophores into the ligands as well as phenyl or other highly conjugated ancillary groups that extend the triplet-state lifetime. ${ }^{[14]}$ In an effort to achieve a full-color 
display, researchers have recently turned their attention to the design of potentially blue-emitting metal complexes. ${ }^{[15]}$ This goal, however, has been even more difficult to achieve. One major challenge lies in the selection of suitable chelate ligands to produce complexes with sufficiently large intraligand (IL) $\pi-\pi^{*}$ and metal-ligand charge transfer (MLCT) energy gaps. Such an approach might be expected to lead to a closer proximity between IL (or MLCT) and metal-centered dd states (or ligand field (LF) states), which would induce an efficient radiationless decay pathway. A potential strategy for circumventing this obstacle would be to ensure the presence of a large crystal-field stabilization energy so that the metal-centered dd states are well above the designated IL (or MLCT) emitting states. ${ }^{[11]}$ Thus, subtlety in the selection of the third-row metal element as well as the ancillary ligands is necessary to ensure that the relative energy levels of the various states (e.g. intra-ligand (IL) $\pi \pi^{*}$, MLCT and metal dd) can be fine-tuned to maximize the efficiency of the blue phosphorescence. To achieve this goal attempts have been made to design polynuclear nitrogen heterocycles with the appropriate electronic properties, ${ }^{[16]}$ and to employ third-row transition metals to strengthen the metal-ligand bonding interactions.

Herein, we demonstrate the synthesis and characterization of a series of new osmium carbonyl complexes 1-3, which contain a specially tailored chelating ligand, (2-pyridyl)triazole (Scheme 1 ), by reactions with $\left[\mathrm{Os}_{3}(\mathrm{CO})_{12}\right]$. This synthetic route is similar to the one we previously used for the synthesis of pyrazole complexes. ${ }^{[17]}$ In addition to the advantage of an even larger HOMO-LUMO $\left(\pi-\pi^{*}\right)$ energy gap relative to that of (2-pyridyl)pyrazole, the (2-pyridyl)triazolate ligand is an asymmetric chelate ligand. The use of such asymmetric ligands should, in the absence of structural stereoselectivity, give two or even more isomers from a single synthetic manipulation. Accordingly, geometric isomers of $\mathbf{1}$ and $\mathbf{2}$ were obtained from the condensation of $\left[\mathrm{Os}_{3}(\mathrm{CO})_{12}\right]$ and 3-tert-butyl-5-(2-pyridyl)-1,2,4-triazole (bptz)H. Remarkably, these isomers exhibit drastically different photophysical properties. In contrast, the related complex $\mathbf{3}$ was isolated as a single isomer from the respective reaction using the $\mathrm{CF}_{3}$-substituted triazole (fptz)H. This molecule exhibits the best saturated blue phosphorescence of all of these derivatives. A detailed relaxation mechanism for this phosphorescence was probed in this study. These re-

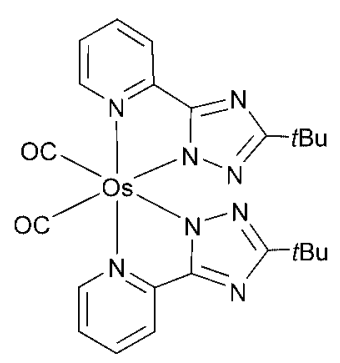

1

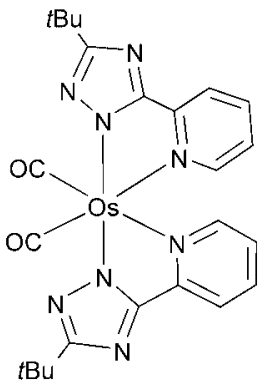

2
Scheme 1. Schematic structural drawings of complexes $\mathbf{1}, \mathbf{2}$, and $\mathbf{3}$.

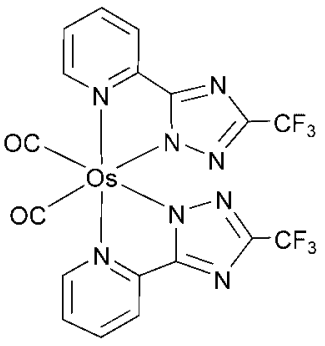

3 sults, in combination with structural information determined by X-ray diffraction analysis coupled with theoretical calculations, demonstrate the importance of the interplay between the various lower-lying excited states in optimizing both the peak wavelength and the quantum efficiency of these third-row transition-metal complexes.

\section{Results}

Preparation and spectroscopic characterization: Analogously to the previously reported reaction involving 3-trifluoromethyl-5-(2-pyridyl)pyrazole, ${ }^{[17]}$ the corresponding triazole ligand, (fptz)H, readily reacted with $\left[\mathrm{Os}_{3}(\mathrm{CO})_{12}\right]$ to afford the highly emissive $\left[\mathrm{Os}(\mathrm{CO})_{2}(\mathrm{fptz})_{2}\right](\mathbf{3})$ as the only isolable product. Characterization of $\mathbf{3}$ was achieved by spectroscopic methods (see the Experimental Section). It was assumed that complex $\mathbf{3}$ is isostructural with the pyrazolate analogue $\left[\mathrm{Os}(\mathrm{CO})_{2}(\mathrm{pypz})_{2}\right],{ }^{[17 \mathrm{~b}]}$ in which both the pyridyl nitrogen atom $\left(\mathrm{N}_{\mathrm{py}}\right)$ and the nearby nitrogen atom of the triazolate fragment coordinate to the central metal atom to form the expected five-membered $\mathrm{C}_{2} \mathrm{~N}_{2} \mathrm{O}$ s ring system.

A similar synthetic route was applied to the related tertbutyl-substituted triazole. In contrast to the previous results, two complexes with identical stoichiometry were observed. This is evident from the electron impact MS analysis, which showed the molecular ion at $\mathrm{m} / \mathrm{z} 651$ and the daughter peak due to the simultaneous loss of two carbonyl ligands at $\mathrm{m} / \mathrm{z}$. 591. Separation of these osmium complexes was achieved by using their marked differences of solubility in acetone, in which the less soluble isomer $\left[\mathrm{Os}(\mathrm{CO})_{2}(\mathrm{bptz})_{2}\right](\mathbf{1})$ can be readily obtained as a crystalline solid, while the second product $\left[\mathrm{Os}(\mathrm{bptz})_{2}(\mathrm{CO})_{2}\right.$ ] (2) was isolated by repeated extraction and slow diffusion of hexane vapor into the saturated acetone solution at room temperature.

The isomerization of complexes $\mathbf{1}$ and $\mathbf{2}$ was slow even at elevated temperatures. This was confirmed by heating crystalline samples of either $\mathbf{1}$ or $\mathbf{2}$ to $185^{\circ} \mathrm{C}$ for a period of three days. Complex $\mathbf{1}$ exhibited a much greater thermal stability under these extreme conditions, with about $75 \%$ of the starting material being recovered. Conversely, complex 2 underwent severe decomposition, affording only about $30 \%$ of recovered $\mathbf{2}$ together with a negligible amount of $\mathbf{1}$. When analogous reactions were conducted in hexane solution in a stainless steel autoclave $\left(185^{\circ} \mathrm{C}\right.$, 3 days), even greater amounts of decomposition were observed for $\mathbf{1}(\geq 50 \%)$ and $\mathbf{2}$ $(\geq 80 \%)$. Nevertheless, the interconversion between complexes $\mathbf{1}$ and $\mathbf{2}$ was again negligible in both of these experiments.

Structural characterization: Single-crystal X-ray diffraction studies were carried out to resolve the exact molecular structures of complexes $\mathbf{1}$ and $\mathbf{2}$ (Table 1). Bond lengths and 
Table 1. Crystal data and structure refinement parameters for complexes $\mathbf{1}$ and $\mathbf{2}$.

\begin{tabular}{|c|c|c|}
\hline Complex & $\mathbf{1}$ & 2 \\
\hline empirical formula & $\mathrm{C}_{24} \mathrm{H}_{26} \mathrm{~N}_{8} \mathrm{O}_{2} \mathrm{Os}$ & $\mathrm{C}_{24} \mathrm{H}_{26} \mathrm{~N}_{8} \mathrm{O}_{2} \mathrm{Os} \cdot 0.5 \mathrm{C}_{3} \mathrm{H}_{6} \mathrm{O}$ \\
\hline formula weight & 648.73 & 677.77 \\
\hline diffractometer & Bruker Smart ApexCCD & Nonius KappaCCD \\
\hline temperature $[\mathrm{K}]$ & $295(2)$ & $150(1)$ \\
\hline crystal system & triclinic & monoclinic \\
\hline space group & $P \overline{1}$ & $P 2_{1} / n$ \\
\hline$a[\AA]$ & $9.9562(4)$ & $9.2101(1)$ \\
\hline$b[\AA]$ & $10.1502(4)$ & $23.0476(3)$ \\
\hline$c[\AA]$ & $14.5424(6)$ & $13.3190(2)$ \\
\hline$\alpha\left[^{\circ}\right]$ & $82.404(1)$ & \\
\hline$\beta\left[^{\circ}\right]$ & $73.950(1)$ & $107.9669(8)$ \\
\hline$\gamma\left[^{\circ}\right]$ & $65.429(1)$ & \\
\hline volume $\left[\AA^{3}\right], Z$ & $1284.19(9), 2$ & $2689.36(6), 4$ \\
\hline$\rho_{\text {calcd }}\left[\mathrm{Mg} \mathrm{m}^{-3}\right]$ & 1.678 & 1.674 \\
\hline absorption coefficient $\left[\mathrm{mm}^{-1}\right]$ & 5.001 & 4.782 \\
\hline$F(000)$ & 636 & 1336 \\
\hline crystal size $\left[\mathrm{mm}^{3}\right]$ & $0.40 \times 0.30 \times 0.30$ & $0.33 \times 0.25 \times 0.25$ \\
\hline $2 \theta\left[^{\circ}\right]$ & $2.21-27.50$ & $1.77-27.50$ \\
\hline reflections collected & 20922 & 27283 \\
\hline independent reflections & 5885 & 6168 \\
\hline$R$ (int) & 0.0306 & 0.0446 \\
\hline no. data/restraints/parameters & $5885 / 0 / 344$ & $6168 / 1 / 323$ \\
\hline goodness-of-fit on $F^{2}$ & 1.068 & 1.183 \\
\hline final $R$ indices $[I>2 \sigma(I)]$ & $R_{1}=0.0203, w R_{2}=0.0493$ & $R_{1}=0.0403, w R_{2}=0.1075$ \\
\hline$R$ indices (all data) & $R_{1}=0.0221, w R_{2}=0.0502$ & $R_{1}=0.0589, w R_{2}=0.1238$ \\
\hline largest difference peak/hole $\left[\mathrm{e} \AA^{-3}\right]$ & $0.783 /-0.908$ & $1.829 /-1.642$ \\
\hline
\end{tabular}

An X-ray structural characterization of $\mathbf{2}$ was conducted to reveal the structural differences between compounds $\mathbf{1}$ and $\mathbf{2}$. An ORTEP diagram, together with the atom-numbering scheme, is illustrated in Figure 2, and selected bond lengths and angles are listed in Table 3. The orientation of the ligands around the osmium atom in $\mathbf{2}$ is distinctively different from that in 1. First of all, the pyridyl-nitrogen atoms N1 and N5 are now located at the positions trans to the cis-oriented carbonyl ligands. Whereas altering the ligand orientation has a negligible effect on the chelate bite angles (cf. $\Varangle N 1-$ Os-N2 77.0(2) and $\Varangle N 5-O s-N 6$ $\left.76.9(2)^{\circ}\right)$ the pyridine-osmium dative bonding interaction appears to be substantially
Table 2. Selected bond lengths $[\AA]$ and angles $\left[^{\circ}\right]$ for complex $\mathbf{1}$.

\begin{tabular}{lclc}
\hline Os-N1 & $2.108(2)$ & Os-N2 & $2.071(2)$ \\
Os-N5 & $2.110(2)$ & Os-N6 & $2.072(2)$ \\
Os-C1 & $1.878(3)$ & Os-C2 & $1.894(3)$ \\
O1-C1 & $1.136(4)$ & O2-C2 & $1.131(4)$ \\
N2-N3 & $1.362(3)$ & N2-C8 & $1.322(3)$ \\
N3-C9 & $1.332(4)$ & N4-C8 & $1.333(4)$ \\
N4-C9 & $1.345(4)$ & & \\
N1-Os-N2 & $77.19(9)$ & N5-Os-N6 & $77.13(9)$ \\
N1-Os-N5 & $164.01(9)$ & N2-Os-C2 & $172.12(11)$ \\
N6-Os-C1 & $172.27(12)$ & & \\
\hline
\end{tabular}

angles of complex $\mathbf{2}$ are listed in Table 2. As depicted in Figure 1, the structure of $\mathbf{1}$ has an octahedral coordination around the osmium atom. The 2-pyridyltriazolate ligands form five-membered chelate rings with the pyridyl nitrogen atoms $\mathrm{N} 1$ and $\mathrm{N} 5$ located in the trans positions, while the cis carbonyl ligands occupy the sites trans to the triazolate nitrogen atoms $\mathrm{N} 2$ and $\mathrm{N} 6$, which are arranged in a $\operatorname{cis}(\mathrm{N}, \mathrm{N})$ fashion. The pairs of donor ligands $\mathrm{CO}$, and atoms $\mathrm{N}_{\mathrm{py}}$, and $\mathrm{N}_{\mathrm{tz}}$ define the observed cis-trans-cis conformation. In terms of coordination geometry, the major deviation from a perfect octahedral coordination is caused by the smaller bite angles observed for the 2-pyridyltriazolate chelates ( $\Varangle \mathrm{N} 1$ Os-N2 77.19(9) and $\left.\Varangle N 5-O s-N 6 ~ 77.13(9)^{\circ}\right)$. Moreover, the triazolate nitrogen atoms seem to possess a slightly stronger donor interaction with the Os ${ }^{\mathrm{II}}$ center than the 2-pyridyl nitrogen atoms. This viewpoint is supported by the Os-N(tz) distances (Os-N2 2.071(2) and Os-N6 2.072(2) A) being significantly shorter than the Os-N(py) distances (Os-N1 2.108(2) and Os-N5 2.110(2) A]. Nevertheless, both sets of distances are slightly longer than the Os-N distances of 2.036-2.076 $\AA$ observed in related complexes, such as [Os$\left.(\mathrm{bpy})_{2}(\mathrm{Cl})(\mathrm{NCMe})\right]\left[\mathrm{PF}_{6}\right]$ and $\left[\mathrm{Os}(\mathrm{bpy})_{3}\right]\left[\mathrm{PF}_{6}\right]_{2} \cdot{ }^{[18]}$

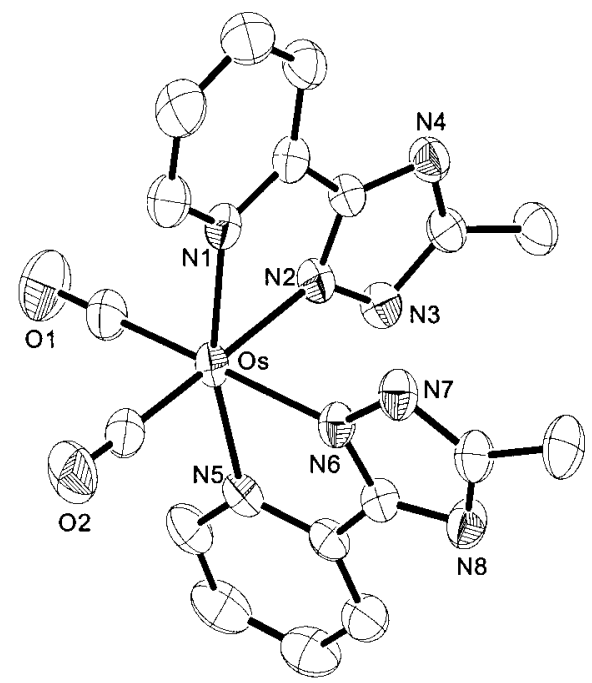

Figure 1. Molecular structure of complex 1 (ORTEP diagram with thermal ellipsoids shown at the $30 \%$ probability level; the methyl groups of the tert-butyl substituent on the triazolate fragments have been removed for clarity).

weaker, as is evident from the Os-N(py) distances (Os-N1 2.152(5) and Os-N5 2.166(5) ̊), which are the longest ever observed for closely related osmium complexes. Moreover, the Os-N(triazolate) distances in $2(\mathrm{Os}-\mathrm{N} 22.046(4)$ and Os-N6 2.067(4) $\AA$ ), in which the triazolate ligands are trans to one another, are slightly shorter than those in $\mathbf{1}(\mathrm{Os}-\mathrm{N} 2$ 2.071(2) and Os-N6 2.072(2) $\AA$ ), in which these ligands are trans to CO. These differences can be rationalized in terms of the relative donor-acceptor properties of the nitrogen ligands and their competition with $\mathrm{CO}$, which is known to be a strong $\pi$ acceptor. The very long Os-N(pyridine) distances 


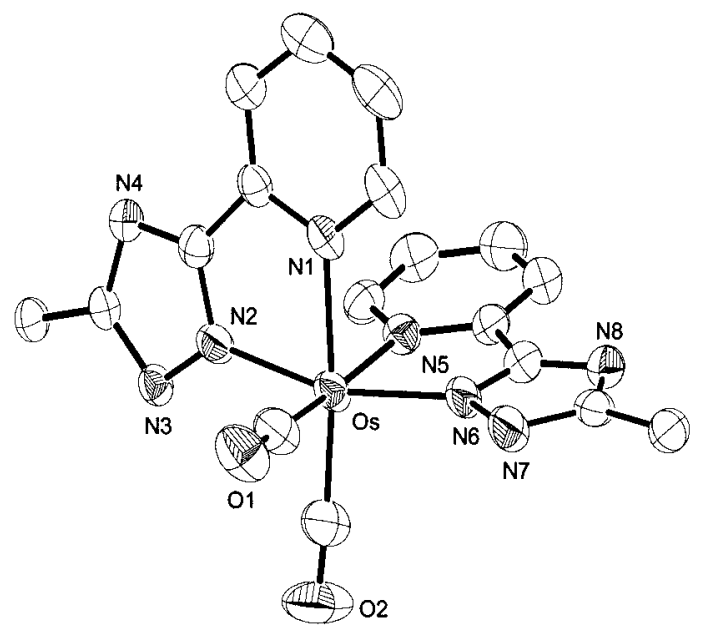

Figure 2. Molecular structure of complex 2 (ORTEP diagram with thermal ellipsoids shown at the $30 \%$ probability level; the methyl groups of the tert-butyl substituent on the triazolate fragments have been removed for clarity).

Table 3. Selected bond lengths $[\AA \AA]$ and angles $\left[^{\circ}\right]$ for complex 2 .

\begin{tabular}{lclr}
\hline Os-N1 & $2.152(5)$ & Os-N2 & $2.046(4)$ \\
Os-N5 & $2.166(5)$ & Os-N6 & $2.067(4)$ \\
Os-C1 & $1.901(7)$ & Os-C2 & $1.875(7)$ \\
O1-C1 & $1.122(8)$ & O2-C2 & $1.129(8)$ \\
N2-N3 & $1.364(6)$ & N2-C8 & $1.338(7)$ \\
N3-C9 & $1.339(6)$ & N4-C8 & $1.335(7)$ \\
N4-C9 & $1.349(7)$ & & \\
N1-Os-N2 & $77.0(2)$ & N5-Os-N6 & $76.9(2)$ \\
N2-Os-N6 & $161.6(2)$ & N1-Os-C2 & $173.8(2)$ \\
N5-Os-C1 & $174.2(2)$ & & \\
\hline
\end{tabular}

in 2 (trans to $\mathrm{CO}$ ) suggest that the pyridine ligands are poorer $\sigma$ donors and/or $\pi$ acceptors than the triazolate ligands (trans to $\mathrm{CO}$ ) in $\mathbf{1}$. This is also consistent with the known higher $\pi^{*}$ energy level of the pyridyl fragment relative to the triazolate, which should render the pyridyl group a poorer $\pi$ acceptor. In addition, the triazolate ligand is negatively charged whereas the pyridine group is a neutral donor. This suggests that the triazolate should be a stronger $\sigma$ donor than pyridine, which is again consistent with the bond length data. Finally, we note that in the IR spectra of both 1 and 2 there are two sharp $v(\mathrm{CO})$ bands, the frequencies of which are higher in the spectrum of $\mathbf{2}$ (2050 and $\left.1982 \mathrm{~cm}^{-1}\right)$ than in that of $\mathbf{1}\left(2041,1970 \mathrm{~cm}^{-1}\right)$, which confirms there is less $\pi$-backbonding to $\mathrm{CO}$ in $\mathbf{2}$. These stereochemical and bonding differences between $\mathbf{1}$ and $\mathbf{2}$ are undoubtedly responsible for the remarkable photophysical and photochemical properties of these compounds which are described below.

Photophysical and photochemical properties: Figure 3 shows the UV/Vis absorption and emission spectra of complexes $\mathbf{1}$, $\mathbf{2}$, and $\mathbf{3}$ in acetonitrile. In general, the dominant absorption band in the spectral region of $225-280 \mathrm{~nm}$, for which $\varepsilon$ values at the absorption maxima were calculated to be $>10^{4} \mathrm{M}^{-1} \mathrm{~cm}^{-1}$, is attributed to the local ${ }^{1} \pi-\pi^{*}$ transition of

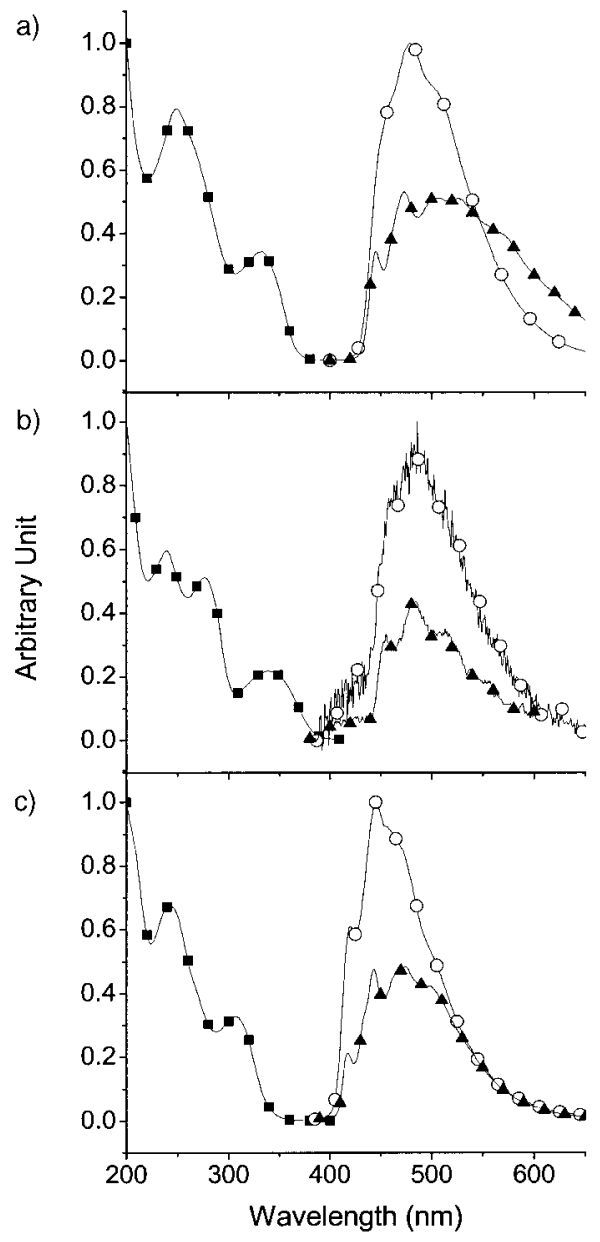

Figure 3. UV/Vis absorption (-m-) and emission (-०-) spectra of a) complex 1, b) 2, and c) 3 in $\mathrm{CH}_{3} \mathrm{CN}$. The trace (- $\mathbf{\Delta -}$ ) denotes the emission spectra obtained from the single crystals at room temperature.

the pyridine and/or triazolate fragment. The broad, structureless band at $\sim 310-340 \mathrm{~nm}$ for 1-3 can be assigned to a triazolate-to-pyridine intra-ligand $\pi-\pi^{*}$ transition, a fact which is firmly supported by theoretical calculations. Note also that the $320-330 \mathrm{~nm}$ band spectrally resembles that of the deprotonated free ligand, that is, bptz or fptz. Moreover, the absorption profile for complexes $\mathbf{1}-\mathbf{3}$ at $\lambda>340 \mathrm{~nm}$ is mainly due to the metal-ligand charge transfer in the singlet state $\left({ }^{1} \mathrm{MLCT}\right)$, which is otherwise absent in the deprotonated ligand. Further insights into the subtle differences between $\mathbf{1}$ and $\mathbf{2}$ will be elaborated in the following sections. Although an effective enhancement of the spin-orbit coupling by the osmium atom is expected, absorption features associated with the ${ }^{3}$ MLCT and intra-ligand ${ }^{3} \pi-\pi^{*}$ bands could not be resolved from that of the singlet states. Finally, the introduction of the electron-withdrawing $\mathrm{CF}_{3}$ group onto the electron-rich triazolate moiety of compound $\mathbf{3}$ stabilizes the ligand's HOMO so that the intra-ligand $\pi-\pi^{*}$ band undergoes a hypsochromic shift of $\sim 3075 \mathrm{~cm}^{-1}$ relative to that of $\mathbf{1}$ or $\mathbf{2}$.

The emission spectrum of compound $\mathbf{1}$ is depicted in Figure 3. Despite the diffusive intra-ligand $\pi-\pi^{*}$ absorption band, the corresponding emission spectrum exhibits a dis- 
tinct vibronic feature, with peak maxima at $\sim 455,480$, and $507 \mathrm{~nm}$ in $\mathrm{CH}_{3} \mathrm{CN}$ at $298 \mathrm{~K}$. The luminescence intensity is linearly proportional to the increase in concentration, ruling out a possible association with any high-order aggregation. That the entire emission band originates from a common ground-state species is ascertained by the same fluorescence excitation spectra throughout the monitored wavelengths of $450-600 \mathrm{~nm}$. The excitation spectra, within experimental error, are also effectively identical to the absorption spectrum, indicating that the entire emission results from a common Franck-Condon excited state. Comparison of the corresponding absorption and emission spectra of $\mathbf{1}$ elicits several remarks. First of all, there is a significantly large energy gap of about $4000 \mathrm{~cm}^{-1}$ for the $0-0$ vibronic onsets between the absorption of the singlet state and the emission bands. In comparison, the deprotonated bptzH ligand exhibits a fluorescence band maximized at $\sim 320 \mathrm{~nm}$, in which the $0-0$ onset overlaps well with that of the intra-ligand $\pi-\pi^{*}$ absorption band. Secondly, the Stokes shift, defined as the peak-to-peak frequency between absorption (singlet $\pi-\pi^{*}$ transition) and emission, is as large as $8000 \mathrm{~cm}^{-1}$. The emission peak wavelength is nearly solvent-polarity independent, with a slightly hypsochromic shift from $478 \mathrm{~nm}$ in cyclohexane to $480 \mathrm{~nm}$ in $\mathrm{CH}_{3} \mathrm{CN}$. Thus, the possibility of the emission being associated with a large solvent dipolar relaxation can also be eliminated. ${ }^{[19]}$

The emission intensity, as well as the corresponding relaxation dynamics for complex $\mathbf{1}$, is strongly quenched by oxygen. Under oxygen-free conditions, the quantum efficiency of the $480 \mathrm{~nm}$ emission in $\mathrm{CH}_{3} \mathrm{CN}$ was measured to be as high as 0.42 , with a lifetime of $39.9 \mathrm{~ns}$ (Table 4). By aerating the solution the quantum efficiency and lifetime were drastically reduced to $2 \times 10^{-3}$ and $218 \mu$ s, respectively. The plot of relaxation dynamics versus $\mathrm{O}_{2}$ concentration reveals a straight line (not shown here). Accordingly, the $\mathrm{O}_{2}$ quenching rate constant was deduced to be $2.4 \times 10^{9} \mathrm{M}^{-1} \mathrm{~s}^{-1}$, which is nearly $1 / 9$ of the diffusion-controlled rate in $\mathrm{CH}_{3} \mathrm{CN}$, consistent with a quenching mechanism that incorporates collision-induced triplet-triplet energy transfer. ${ }^{[17 b]}$ This result, in combination with the steady-state resolved large $0-0$ splitting and vibronic progression feature, leads us to conclude that the emission from complex 1 mainly originates from a triplet $\pi-\pi^{*}$ transition in the cyclometalated complexes. ${ }^{[20]}$ No fluorescence that could be attributed to either intra-ligand ${ }^{1} \pi-\pi^{*}$ or ${ }^{1}$ MLCT fluorescence was resolved, which indicates an ultrafast rate for the osmium-enhanced intersystem-crossing process.
Remarkable differences in the emission properties were observed for $\mathbf{2}$. In contrast to $\mathbf{1}$ with its highly efficient phosphorescence, complex $\mathbf{2}$ is nearly nonemissive at room temperature in $\mathrm{CH}_{3} \mathrm{CN}$. The emission quantum efficiency was measured to be as low as $4.6 \times 10^{-4}$ in degassed $\mathrm{CH}_{3} \mathrm{CN}$ at $298 \mathrm{~K}$. Intriguingly, despite the drastic dissimilarity in the emission intensity, the phosphorescence of $\mathbf{2}$ possesses similar vibronic spectral features to that of $\mathbf{1}$, with the peak maxima being red-shifted by only about $3-5 \mathrm{~nm}$ (see Figure 3). The weak phosphorescence intensity also correlates well with the observed fast relaxation dynamics; the lifetime of the phosphorescence for $\mathbf{2}$ was measured to be as short as $26.3 \mathrm{~ns}$ in $\mathrm{CH}_{3} \mathrm{CN}$. Quenching by $\mathrm{O}_{2}$ is thus negligible owing to the fast nonradiative decay rate, as indicated by the nearly unchanged emission intensity and relaxation dynamics before and after aeration. Note that although the rate of intersystem crossing is very fast, as indicated by the system-response-limited rising component of the phosphorescence $(\ll 200 \mathrm{ps})$, a small but non-negligible fluorescence shoulder $\left(\lambda_{\max } \sim 420 \mathrm{~nm}, \tau_{\mathrm{f}} \ll 200 \mathrm{ps}\right)$ could be resolved in 2 (see Figure 3b).

Temperature-dependent studies were performed to gain further insights into the deactivation mechanism for complex 2. As shown in Figure 4, the phosphorescence was strongly temperature dependent. The quantum yield increased from $4.6 \times 10^{-4}$ at $298 \mathrm{~K}$ to about 0.40 at $150 \mathrm{~K}$ and remained constant at lower temperatures. The results obtained under steady-state conditions were further compared

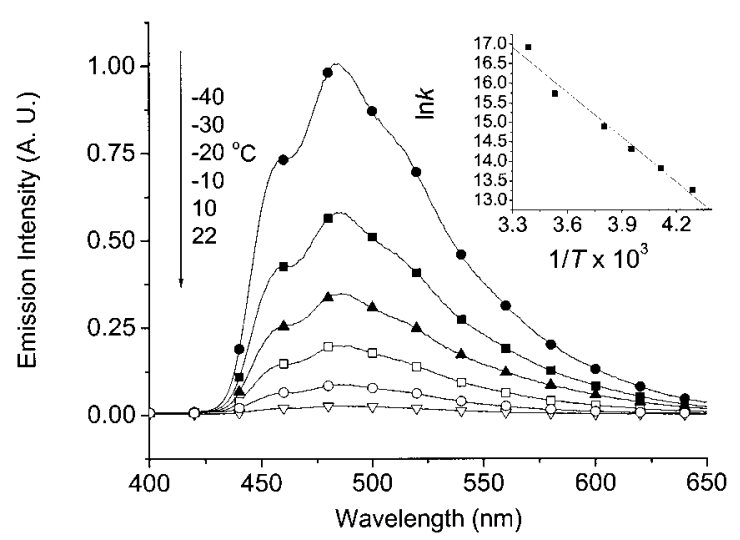

Figure 4. The temperature dependent emission spectra of complex 2 . Insert: The linear graphical plot of $\ln k$ versus $1 / T$, where $k=$ $\left\{\left(\frac{1}{\Phi_{\mathrm{p}}}-1-\frac{k_{\mathrm{nr}}}{k_{\mathrm{r}}}\right) k_{\mathrm{r}}\right\}$
Table 4. The photophysical properties of the osmium complexes at room temperature. ${ }^{[a]}$

\begin{tabular}{|c|c|c|c|c|c|c|}
\hline & $\lambda_{\max }^{\mathrm{abs}}[\mathrm{nm}]$ & $\lambda_{\max }^{\mathrm{em}}[\mathrm{nm}]$ & $\Phi_{\text {aerated }}$ & $\Phi_{\text {degassed }}$ & $\tau_{\text {aerated }}$ & $\tau_{\text {degassed }}$ \\
\hline 1 & 250,333 & $\begin{array}{l}455,480,507 \\
(456,482,512,551)\end{array}$ & $2.31 \times 10^{-3}$ & $4.2 \times 10^{-1}$ & $\begin{array}{l}218 \mathrm{~ns} \\
(42.4 \mu \mathrm{s})\end{array}$ & $39.9 \mu \mathrm{s}$ \\
\hline 2 & $240,276,340$ & $\begin{array}{l}460,483,515 \\
(410,445,472,503,527,570)\end{array}$ & $2.93 \times 10^{-4}$ & $4.6 \times 10^{-4}$ & $\begin{array}{l}21.7 \mathrm{~ns} \\
(88.7 \mathrm{~ns}) \\
(6.9 \mu \mathrm{s})^{[\mathrm{b}]}\end{array}$ & $26.3 \mathrm{~ns}$ \\
\hline 3 & 243,307 & $\begin{array}{l}420,446,468 \\
(418,443,475,500)\end{array}$ & $9.56 \times 10^{-2}$ & $2.33 \times 10^{-1}$ & $\begin{array}{l}860 \mathrm{~ns} \\
(4.5 \mu \mathrm{s})\end{array}$ & $2.88 \mu \mathrm{s}$ \\
\hline
\end{tabular}

[a] Data for the single-crystal samples are listed in parentheses. [b] At $77 \mathrm{~K}$. with the temperature-dependent relaxation dynamics. The lifetime of the phosphorescence of complex $\mathbf{2}$ followed the steady-state pattern, increasing significantly from $26.3 \mathrm{~ns}$ at $298 \mathrm{~K}$ to as long as $34 \mu$ s at $150 \mathrm{~K}$. By assuming a temperature-independent radiative decay rate $\left(k_{\mathrm{r}}\right)$ for the phos- 
phorescence, the observed temperature-dependent decay rate $k_{\mathrm{obs}}$ can be expressed by Equation (1), where $k_{\mathrm{nr}}(T)$ represents the temperature-dependent nonradiative deactivation rate, and $k_{\mathrm{nr}}$ denotes the temperature-independent radiationless decay rate constant, possibly involving intersystem crossing, and so on. Accordingly, the measured quantum yield can be deduced by Equation (2).

$k_{\mathrm{obs}}=k_{\mathrm{r}}+k_{\mathrm{nr}}+k_{\mathrm{nr}}(T)$

$\Phi_{\mathrm{p}}=\frac{k_{\mathrm{r}}}{k_{\mathrm{r}}+k_{\mathrm{nr}}+k_{\mathrm{nr}}(T)}$

The temperature-dependent radiationless decay rate constant $k_{\mathrm{nr}}(T)$ can be expressed as an Arrhenius-type thermally deactivated pathway by Equation (3), which can then be substituted into Equation (2) to obtain Equation (4).

$k_{\mathrm{nr}}(T)=A \mathrm{e}^{-E_{\mathrm{a}} / R T}$

$\ln \left\{\left(\frac{1}{\Phi_{\mathrm{p}}}-1-\frac{k_{\mathrm{nr}}}{k_{\mathrm{r}}}\right) k_{\mathrm{r}}\right\}=\ln A-\frac{E_{\mathrm{a}}}{R T}$

As indicated by steady-state and time-resolved measurements, the lifetime and intensity of the emission at $<150 \mathrm{~K}$ are nearly temperature independent. Thus $k_{\mathrm{nr}}(T)$ is assumed to be negligible, and $\Phi_{\mathrm{p}}$ expressed in Equation (2) can be simplified to Equation (5), which was measured to be about 0.40 at $150 \mathrm{~K}$. On the other hand, $k_{\mathrm{obs}}$ was determined to be $2.97 \times 10^{4} \mathrm{~s}^{-1}$ at $150 \mathrm{~K}$. Accordingly $k_{\mathrm{r}}$ and $k_{\mathrm{nr}}$ were deduced to be $1.21 \times 10^{4}$ and $1.76 \times 10^{4} \mathrm{~s}^{-1}$, respectively. Having determined all the parameters, the plot of Equation (4) reveals a straight line and $E_{\mathrm{a}}$ was deduced to be $7.64 \mathrm{kcal} \mathrm{mol}^{-1}$ with a frequency factor $A$ of $7.24 \times 10^{12} \mathrm{~s}^{-1}$ (see insert of Figure 4).

$\Phi_{\mathrm{p}}=\frac{k_{\mathrm{r}}}{k_{\mathrm{nr}}+k_{\mathrm{r}}}$

Similar emission trends were observed for the single crystals of complexes $\mathbf{1}$ and $\mathbf{2}$, with the intensity of the phosphorescence of $\mathbf{2}$ about 140 -fold lower than that of $\mathbf{1}$. These results indicate that the large amplitude motions ${ }^{[21]}$ do not trigger the radiationless deactivation in $\mathbf{2}$. Both the intensity and the relaxation dynamics of the phosphorescence of $\mathbf{2}$ also revealed a strong temperature dependence; the lifetime increased from $88.7 \mathrm{~ns}$ at $298 \mathrm{~K}$ to $6.9 \mu \mathrm{s}$ at $77 \mathrm{~K}$. Interestingly, although the spectral features for $\mathbf{1}$ and $\mathbf{2}$ are similar in solution, they are notably different in the single crystal; the emission of $\mathbf{1}$ is broader and red-shifted compared with that of 2 (see Figure 3 for comparison). The results imply that $\mathbf{1}$ and $\mathbf{2}$ may be subject to different crystal-packing environments, which perturbs both the ground and electronically excited states to various degrees. This viewpoint is supported by the fact that $\mathbf{1}$ and $\mathbf{2}$ crystallize in different space groups, $P \overline{1}$. and $P 2_{1} / n$, respectively, in the solid state (see Table 1)

In another approach, the possible deactivation through photoinduced $\mathbf{2} \rightarrow \mathbf{1}$ isomerization was investigated by photolysis. When complex 2 was irradiated by using the third harmonic $(355 \mathrm{~nm})$ of the Nd:YAG laser $\left(\sim 0.12 \mathrm{~mJ}\right.$ pulse $^{-1}$,
$0.6 \mathrm{~cm}$ beam diameter), certain photochemical reactions took place, as indicated by the decrease in the intensity of the $340 \mathrm{~nm}$ absorption band and the growth of a new shoulder at $\lambda_{\max } \sim 420 \mathrm{~nm}$ (Figure 5). During the photolysis

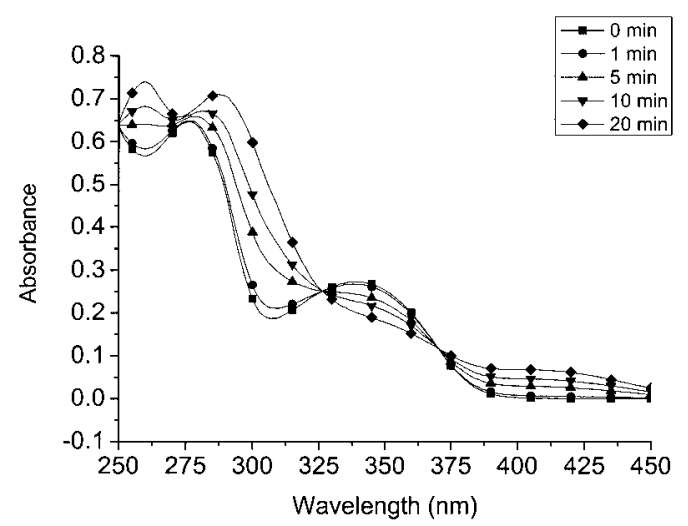

Figure 5. The time-dependent absorption spectra of complex 2 upon photolysis with a $355 \mathrm{~nm}$ laser beam $(10 \mathrm{~Hz}$ repetition rate, see text for details).

of $\mathbf{2}$, we observed neither characteristic absorption bands nor the time-dependent increase of the $480 \mathrm{~nm}$ phosphorescence ascribed to complex $\mathbf{1}$. Therefore, it seems very unlikely that $\mathbf{2} \rightarrow \mathbf{1}$ isomerization occurs upon photolysis. Knowing the time-dependent absorbance change of $\mathbf{2}$ at $355 \mathrm{~nm}$, the photon flux of the laser and the irradiated volume in the photolysis experiment, we estimated the yield of the photoreaction of 2 to be $\sim 5 \times 10^{-4}$, which is negligible in comparison to the $>99 \%$ quenching efficiency of the emission. Accordingly, photochemical reactions, especially in steady-state conditions, should be a very minor channel and thus cannot account for the dominant radiationless deactivation in complex $\mathbf{2}$. In contrast, under identical photolysis conditions, similar photochemical reactions did not take place in complex $\mathbf{1}$, as indicated by the insignificant changes in its absorbance and spectral features. Apparently, the structural differences and the associated bonding play a crucial role in determining the photochemical reactivity. We thus suspect that one plausible reaction channel for the radiationless deactivation in complex $\mathbf{2}$ may involve the weakening of either the metal-pyridine or the metal-CO interaction; the latter is more likely as this would commonly lead to decomposition after prolonged irradiation. As discussed in the following section, the associated shallow metal-ligand (CO or pyridine) potential energy surface plays a key role in the dominant radiationless transition.

\section{Discussion}

To explain the above results, we propose that certain excited states exist that, after being populated, are channeled into radiationless deactivation pathways. One plausible candidate should be the metal-centered $\mathrm{d}-\mathrm{d}$ transition (i.e., ligand field (LF) transition), which normally results in weakening of the metal-ligand interaction as a result of its anti-bonding 
character and may thus act as an activator for the overall radiationless transition. ${ }^{[22]}$ To gain more insight into the differences in the photophysical properties of $\mathbf{1}$ and $\mathbf{2}$, ab initio calculations (DFT, see Experimental Section) on the corresponding molecular orbitals involved in the transition were carried out.

For complexes $\mathbf{1}$ and $\mathbf{2}$, the features of the two lowest unoccupied (LUMO and LUMO+1) and the two highest occupied (HOMO and HOMO-1) frontier orbitals mainly involved in the transition are depicted in Figure 6, while the descriptions and the energy gap of each transition are listed in Table 5 and Table 6. Apparently, the electron densities of the singlet and triplet states for both the HOMO and HOMO-1 are located largely on the triazolate moiety, whereas those of the LUMO and LUMO +1, are largely distributed on the pyridyl moiety, indicating that the lowest transitions, in part, are $\pi$ (triazolate) $\rightarrow \pi^{*}$ (pyridine) in character. The lowest triplet states calculated for $\mathbf{1}(453 \mathrm{~nm})$ and $2(450 \mathrm{~nm})$ are similar in energy, with a difference of as little as about $0.5 \mathrm{kcalmol}^{-1}$. In contrast, the calculated $\mathrm{S}_{0}-\mathrm{S}_{1}$

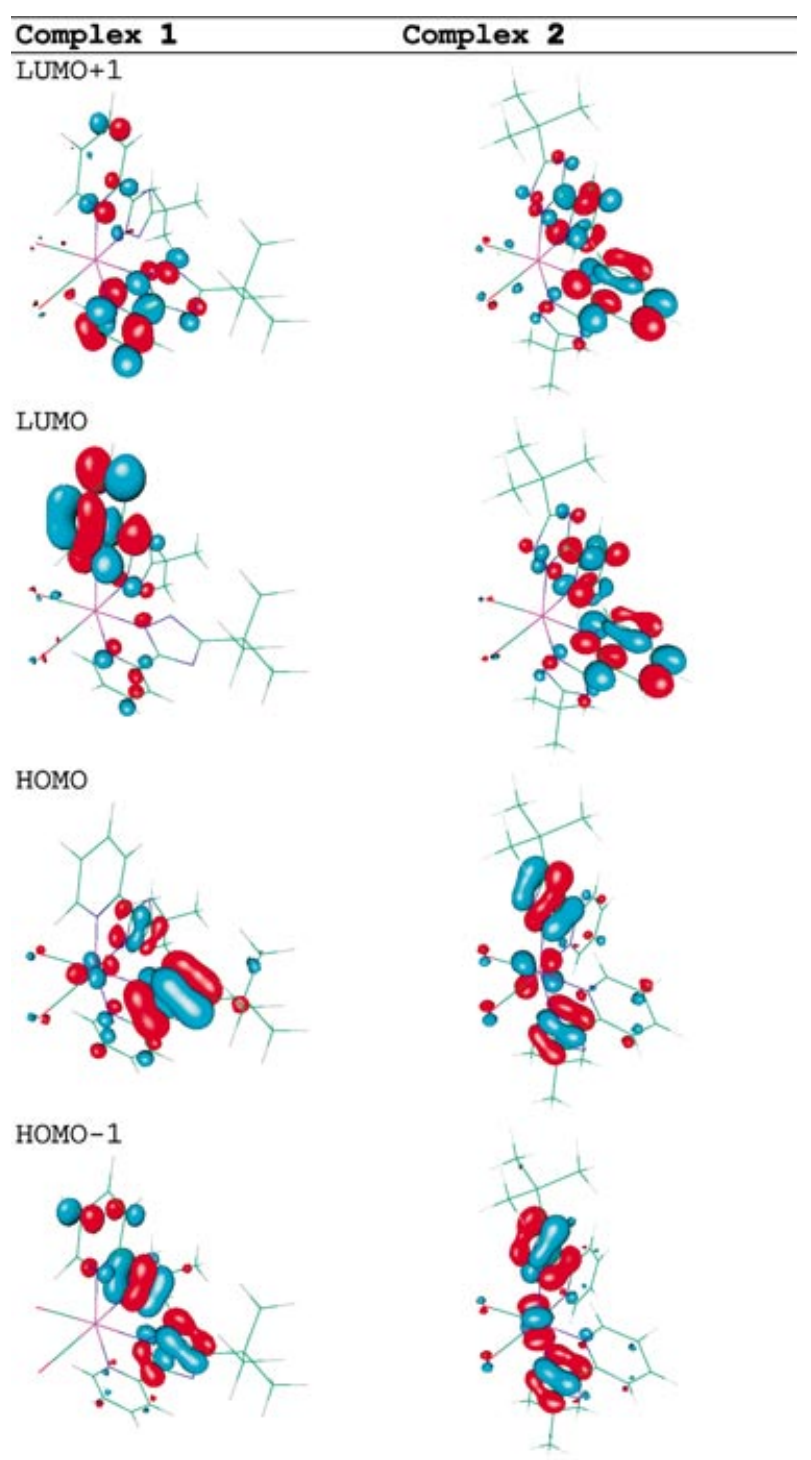

Figure 6. Selected frontier orbitals of complexes $\mathbf{1}$ and $\mathbf{2}$.
Table 5. The calculated energy levels of the lowest four transitions of complex 1.

\begin{tabular}{|c|c|c|c|c|}
\hline Complex 1 & $\lambda[\mathrm{nm}]$ & $E[\mathrm{eV}]$ & $f$ & Assignments \\
\hline $\mathrm{T}_{1}$ & 453.3 & 2.73 & $\sim 0$ & $\begin{array}{l}\text { HOMO } \rightarrow \text { LUMO }+1(+63 \%) \\
\text { HOMO }-1 \rightarrow \text { LUMO +1 }(+19 \%) \\
\text { HOMO } \rightarrow \text { LUMO }(+13 \%) \\
\text { HOMO } \rightarrow \text { LUMO }+3(+7 \%)\end{array}$ \\
\hline $\mathrm{T}_{2}$ & 446.8 & 2.77 & $\sim 0$ & $\begin{array}{l}\text { HOMO }-1 \rightarrow \text { LUMO }(+57 \%) \\
\text { HOMO } \rightarrow \text { LUMO }(24 \%) \\
\text { HOMO } 1 \rightarrow \text { LUMO }+1(12 \%) \\
\text { HOMO- } \rightarrow \text { LUMO +2 }(+7 \%)\end{array}$ \\
\hline $\mathrm{S}_{1}$ & 367.3 & 3.38 & 0.025 & HOMO $\rightarrow$ LUMO $(+94 \%)$ \\
\hline $\mathrm{S}_{2}$ & 361.4 & 3.43 & 0.0206 & $\begin{array}{l}\mathrm{HOMO} \rightarrow \mathrm{LUMO}+1(+84 \%) \\
\mathrm{HOMO}-1 \rightarrow \mathrm{LUMO}+1(6 \%)\end{array}$ \\
\hline
\end{tabular}

Table 6. The calculated energy levels of the lowest four transitions in complex 2.

\begin{tabular}{|c|c|c|c|c|}
\hline Complex 2 & $\lambda[\mathrm{nm}]$ & $E[\mathrm{eV}]$ & $f$ & Assignments \\
\hline $\mathrm{T}_{1}$ & 449.8 & 2.76 & $\sim 0$ & $\begin{array}{l}\text { HOMO } \rightarrow \text { LUMO }+1(+25 \%) \\
\text { HOMO }-1 \rightarrow \text { LUMO }(+25 \%) \\
\text { HOMO } \rightarrow \text { LUMO }(+28 \%) \\
\text { HOMO }-1 \rightarrow \text { LUMO }+1(+22 \%)\end{array}$ \\
\hline $\mathrm{T}_{2}$ & 375.3 & 3.3 & $\sim 0$ & $\begin{array}{l}\text { HOMO }-1 \rightarrow \text { LUMO }+1(+30 \%) \\
\text { HOMO } \rightarrow \text { LUMO }(18 \%) \\
\text { HOMO }-1 \rightarrow \text { LUMO }(26 \%) \\
\text { HOMO } \rightarrow \text { LUMO }+1(+26 \%)\end{array}$ \\
\hline $\mathrm{S}_{1}$ & 374.1 & 3.31 & 0.007 & $\begin{array}{l}\mathrm{HOMO} \rightarrow \text { LUMO }(+85 \%) \\
\mathrm{HOMO}-1 \rightarrow \text { LUMO }+1(11 \%)\end{array}$ \\
\hline $\mathrm{S}_{2}$ & 372.6 & 3.33 & 0.0047 & $\begin{array}{l}\text { HOMO } \rightarrow \text { LUMO }+1(+71 \%) \\
\text { HOMO }-1 \rightarrow \text { LUMO }(26 \%)\end{array}$ \\
\hline
\end{tabular}

energy gap of $2(374 \mathrm{~nm})$ is red-shifted with respect to that of $1(367 \mathrm{~nm})$ by $1.62 \mathrm{kcalmol}^{-1}$. The results not only precisely predict the energy levels of the lower lying excited states but are also consistent with a longer $S_{0} \rightarrow S_{1}$ peak wavelength in $\mathbf{2}$, whereas the phosphorescence exhibits similar peak wavelengths for $\mathbf{1}$ and $\mathbf{2}$ in solution. Therefore, the theoretical level adopted here is suitable for studying the photophysical properties of the complexes concerned.

To deduce the possible nonradiative relaxation pathway, four lowest excited states, including two singlet and two triplet states (see Table 5 and Table 6), were examined. For both complexes $\mathbf{1}$ and $\mathbf{2}$, none of these states possess $\mathrm{d}-\mathrm{d}$ transition character, which rules out the possibility that dd excited states serve as a dominant radiationless deactivation pathway. The strong ligand field strength of the bptz and CO ligands should account for the inaccessibility of the dd excited state (vide supra). Although the lowest triplet states of $\mathbf{1}$ and $\mathbf{2}$ have similar energy properties, the associated frontier orbitals are remarkably different; the HOMO-1 of $\mathbf{1}$ comprises only $\pi$ orbitals, while that of $\mathbf{2}$, similar to the HOMO, consists of a significant contribution from an $\mathrm{Os}^{\mathrm{II}}$ $\mathrm{d} \pi$ orbital and to a lesser extent from CO ligands. Accordingly, a $\mathrm{T}_{1}$ configuration in $\mathbf{2}$ could reasonably be attributed to a ${ }^{3} \pi-\pi^{*}$ transition, mixed to a great extent with the ${ }^{3}$ MLCT character. ${ }^{[23]}$ Populating the $\mathrm{T}_{1}$ excited state causes a shift of the electron density from the metal center, $\mathrm{CO}$, and the triazole to the pyridine moiety, which results in a further reduction of the already weakened Os-CO and Os-pyridine bonding interactions in 2 (vide supra). As a result, the po- 
tential energy surface (PES) of $T_{1}$ in complex 2 might be so shallow that, under extreme conditions, a surface crossing of the PES between $S_{0}$ and $T_{1}$ is possible (see Figure 7). As

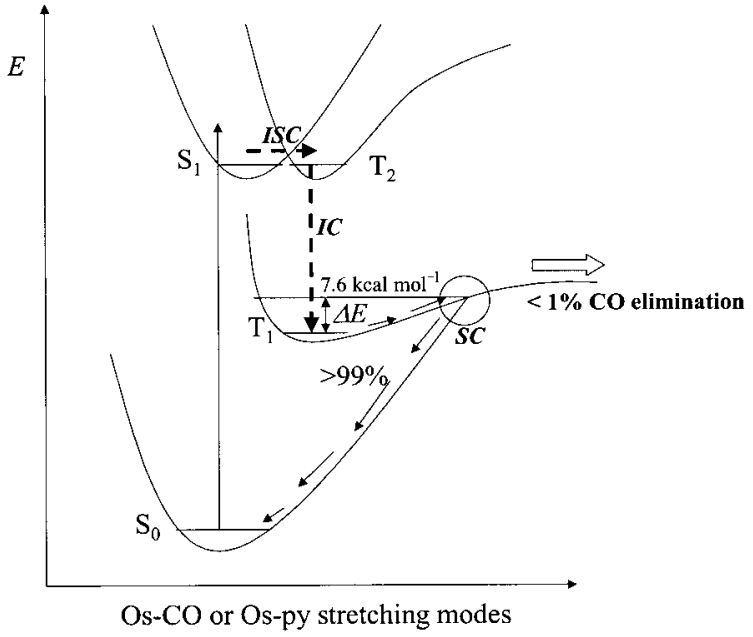

Figure 7. Energy levels of the lower-lying excited states and the proposed relaxation pathway for complex 2 . ISC: intersystem crossing; IC: internal conversion; SC: surface crossing. The efficiency of the radiationless relaxation and the possible $\mathrm{CO}$ elimination is shown according to experimental results. A barrier of $\Delta E \sim 7.6 \mathrm{kcal} \mathrm{mol}^{-1}$ is deduced from the temperature-dependent study (see text).

shown in Figure 7, and supported by the system-responselimited fluorescence rising time, upon excitation, fast $S_{1}-T_{n}$ intersystem crossing (ISC) must take place. It is plausible that ISC proceeds from $S_{1}$ to $T_{2}$ as a result of their similar energies (see Table 6), followed by a fast $T_{2} \rightarrow T_{1}$ internal conversion $\left(\leq 1 \mathrm{ps}^{-1}\right)$. After population equilibrium, 2 can be thermally activated to certain vibrational levels close to the section of surface crossing thus enabling radiationless deactivation through facile metal-ligand bond stretching or even CO elimination. The experimentally extracted activation energy of $7.6 \mathrm{kcal} \mathrm{mol}^{-1}$ provides a quantitative estimate of the energy difference between the ground vibrational level of $\mathrm{T}_{1}$ and the surface crossing section. Thus, upon thermal activation, a dominant $\mathrm{T}_{1} \rightarrow \mathrm{S}_{0}$ radiationless transition caused by a "loose bolt" effect might take place. ${ }^{[24]}$ Furthermore, owing to the shallow PES, a small but non-negligible portion of this thermal activation might also initiate $\mathrm{CO}$ elimination, as supported by the photolysis experiments. Nevertheless, the actual PES involved in the nonradiative process requires further advanced and time-consuming theoretical investigation.

Our discovery may allow a parallel to be drawn between the behavior of tris-cyclometalated iridium complexes, for which the isolation of two geometrical isomers has also been documented in the literature. ${ }^{[25]}$ Structural and spectroscopic data suggest that the facial isomers have stronger and more evenly distributed metal-ligand bond interactions, and are highly emissive in both the fluid and solid states at room temperature. In contrast, the meridional isomers have much greater bond length alternations due to differences in the trans influences of the anionic phenyl moiety and the neu- tral nitrogen donors, such as pyridine or pyrazole, and are significantly less emissive under identical conditions at room temperature. Naturally, this greater bond strength alternation of the meridional isomers induces a similar "loose bolt" effect upon electronic excitation, which is more likely to be responsible for the rapid radiationless deactivation observed in this Ir ${ }^{\mathrm{III}}$ system. Despite this similarity, facile meridionalto-facial rearrangements were observed within these $\mathrm{Ir}^{\mathrm{III}}$ systems by both thermal and photochemical routes, which is in sharp contrast to our Os ${ }^{\text {II }}$ system. This result supports the hypothesis that a much greater kinetic barrier has to be overcome for ligand rearrangement to occur in the Os ${ }^{\mathrm{II}}$ complexes.

\section{Conclusions}

In conclusion, the design of a highly efficient blue phosphorescence emitter based on a third-row transition metal is a challenging issue of current interest. In this study, we have demonstrated that pushing the emission gap towards the blue requires not only ingenious ligand design but also subtle consideration of the interference amongst various low-lying electronic states. Of particular interest is the relative $\mathrm{CO} /$ ligand position in isomers $\mathbf{1}$ and $\mathbf{2}$. From both theoretical and experimental approaches, our results clearly indicate that complexes $\mathbf{1}$ and $\mathbf{2}$, despite being geometric isomers, have completely different relaxation dynamics. Fast thermal activation from the ground vibration level of the $T_{1}$ state to the $T_{1}-S_{0}$ crossing section trigger radiationless deactivation via weakening of the metal-ligand bonding interaction and hence drastically reduce the phosphorescent quantum efficiency of $\mathbf{2}$. Moreover, fine adjustment can also be achieved by functionalizing the ligands. For example, complex 3 was synthesized by substituting the electron-donating tert-butyl group with an electron-withdrawing $\mathrm{CF}_{3}$ group. The electron-withdrawing nature of the $\mathrm{CF}_{3}$ group stabilizes the HOMO of the triazolate moiety, and moves the ${ }^{1} \pi \pi^{*}$ level to a higher energy, as can be seen from the hypsochromic shift in the absorption and corresponding ${ }^{3} \pi-\pi^{*}$ phosphorescence spectra depicted in Figure $3 \mathrm{c}$. Note that the short radiative lifetime $(2.88 \mu \mathrm{s})$ and the pure blue emission $(\sim 450 \mathrm{~nm})$ of complex 3 are promising physical properties for application in blue OLEDs. Detailed OLED studies will be published in a separate paper.

\section{Experimental Section}

General information and materials: Mass spectra were obtained on a JEOL SX-102A instrument operating in electron impact (EI) or fast atom bombardment (FAB) mode. ${ }^{1} \mathrm{H}$ and ${ }^{13} \mathrm{C}$ NMR spectra were recorded on a Varian Mercury-400 or INOVA-500 instrument; chemical shifts are quoted with respect to the internal standard tetramethylsilane for both ${ }^{1} \mathrm{H}$ and ${ }^{13} \mathrm{C}$ NMR data. IR spectra were recorded on a Perkin Elmer 2000 spectrometer. Elemental analyses were carried out at the NSC Regional Instrumentation Center at National Chiao Tung University, Hsinchu, Taiwan. The chelating ligands, 3-trifluoromethyl-5-(2-pyridyl)-1,2,4triazole (fptz)H and 3-tert-butyl-5-(2-pyridyl)-1,2,4-triazole (bptz)H were prepared according to the methods reported in the literature. ${ }^{[2]}$ All reac- 
tions were performed under a nitrogen atmosphere using anhydrous solvents or solvents treated with an appropriate drying reagent.

Synthesis of complexes 1 and 2: A stainless steel autoclave $(160 \mathrm{~mL})$ was charged with 3-tert-butyl-5-(2-pyridyl)-1,2,4-triazole (bptzH, $273 \mathrm{mg}$, $1.35 \mathrm{mmol}),\left[\mathrm{Os}_{3}(\mathrm{CO})_{12}\right](200 \mathrm{mg}, 0.22 \mathrm{mmol})$, and hexane $(80 \mathrm{~mL})$. The autoclave was sealed and heated to $180-190^{\circ} \mathrm{C}$ for three days. The solvent was then removed, and the residue was dissolved in the minimum amount of acetone. This acetone solution was passed through a short silica gel column to remove any insoluble material and then concentrated to about $15 \mathrm{~mL}$. Colorless block-shaped crystals of [Os(CO) $\left.)_{2}(\mathrm{bptz})_{2}\right](\mathbf{1}$, $172 \mathrm{mg}, 0.19 \mathrm{mmol}, 28 \%$ ) were obtained by cooling the solution to $-20^{\circ} \mathrm{C}$. In addition, the acetone supernatant was evaporated to dryness and the resulting solid residue was purified by recrystallization using a mixture of acetone and hexane (2:1). Small amounts of block-shaped crystals of 1 were noted, together with some plate-shaped crystalline materials. The block-shaped crystalline solid of $\mathbf{1}$ was collected by filtration, while the plate-shaped crystals were readily dissolved by a cold acetone wash. This separation process was repeated twice until all of the blockshaped crystals were collected, giving an additional $25 \mathrm{mg}$ of $\mathbf{1}$ $(0.028 \mathrm{mmol}, 4 \%)$. Finally, all of the acetone soluble material was combined and slowly recrystallized by diffusion of gaseous hexane into the acetone solution to afford the desired plate-shaped material, $\left[\mathrm{Os}(\mathrm{bptz})_{2}\right.$ $(\mathrm{CO})_{2}$ ] (2, $\left.99 \mathrm{mg}, 0.15 \mathrm{mmol}, 23 \%\right)$.

Spectral data of 1: MS (EI, $\left.{ }^{192} \mathrm{Os}\right): \mathrm{m} / \mathrm{z}: 651\left[\mathrm{M}^{+}\right], 591\left[\mathrm{M}^{+}-2 \mathrm{CO}\right]$; IR $\left(\mathrm{CH}_{2} \mathrm{Cl}_{2}\right): v=2041$ (s), $1970 \mathrm{~cm}^{-1}$ (s) $(\mathrm{CO}) ;{ }^{1} \mathrm{H}$ NMR $\left(400 \mathrm{MHz},\left[\mathrm{D}_{6}\right]\right.$ acetone, $298 \mathrm{~K}): \delta=9.16\left(\mathrm{dd}, J_{\mathrm{H}, \mathrm{H}}=6.8,1.2 \mathrm{~Hz} ; \mathrm{H}_{\mathrm{py}}\right), 8.25\left(\mathrm{ddd}, J_{\mathrm{H}, \mathrm{H}}=7.4\right.$, $\left.6.8,1.2 \mathrm{~Hz} ; \mathrm{H}_{\mathrm{py}}\right), 8.10\left(\mathrm{dd}, J_{\mathrm{H}, \mathrm{H}}=7.4,1.2 \mathrm{~Hz} ; \mathrm{H}_{\mathrm{py}}\right), 7.55\left(\mathrm{ddd}, J_{\mathrm{H}, \mathrm{H}}=6.8\right.$, 7.4, $\left.1.2 \mathrm{~Hz} ; \mathrm{H}_{\mathrm{py}}\right), 1.12 \mathrm{ppm}(\mathrm{s}, 9 \mathrm{H} ; t \mathrm{Bu})$; elemental analysis calcd $(\%)$ for $\mathrm{C}_{24} \mathrm{H}_{26} \mathrm{~N}_{8} \mathrm{O}_{2} \mathrm{Os}$ : C 44.43, N 17.27, $\mathrm{H}$ 4.04; found: C 44.26, N 17.60, H 4.30. Spectral data of 2: MS (EI, $\left.{ }^{192} \mathrm{Os}\right): \mathrm{m} / z: 651\left[\mathrm{M}^{+}\right], 591\left[\mathrm{M}^{+}-2 \mathrm{CO}\right]$; IR $\left(\mathrm{CH}_{2} \mathrm{Cl}_{2}\right): v=2050(\mathrm{~s}), 1982 \mathrm{~cm}^{-1}$ (s) $(\mathrm{CO}) ;{ }^{1} \mathrm{H}$ NMR $\left(400 \mathrm{MHz},\left[\mathrm{D}_{6}\right.\right.$ ] acetone, $298 \mathrm{~K}): \delta=8.11\left(\mathrm{ddd}, J_{\mathrm{H}, \mathrm{H}}=7.1,6.4,1.2 \mathrm{~Hz} ; \mathrm{H}_{\mathrm{py}}\right), 8.49\left(\mathrm{~d}, J_{\mathrm{H}, \mathrm{H}}=\right.$ $\left.7.1 \mathrm{~Hz} ; \mathrm{H}_{\mathrm{py}}\right), 7.38\left(\mathrm{ddd}, J_{\mathrm{H}, \mathrm{H}}=6.4,7.1,1.2 \mathrm{~Hz} ; \mathrm{H}_{\mathrm{py}}\right), 7.21\left(\mathrm{~d}, J_{\mathrm{H}, \mathrm{H}}=6.4 \mathrm{~Hz}\right.$; $\mathrm{H}_{\mathrm{py}}$ ), $1.48 \mathrm{ppm}(\mathrm{s}, 9 \mathrm{H} ; t \mathrm{Bu})$; elemental analysis calcd $(\%)$ for $\mathrm{C}_{24} \mathrm{H}_{26} \mathrm{~N}_{8} \mathrm{O}_{2} \mathrm{Os}$ : C 44.43, N 17.27, H 4.04; found: C 44.49, N 17.40, H 4.28. Synthesis of complex 3: 3-Trifluoromethyl-5-(2-pyridyl)-1,2,4-triazole $(298 \mathrm{mg}, 1.39 \mathrm{mmol})$ and finely pulverized $\left[\mathrm{Os}_{3}(\mathrm{CO})_{12}\right] \quad(200 \mathrm{mg}$, $0.22 \mathrm{mmol})$ were loaded into a Carius tube $(16 \mathrm{~mL})$ and degassed. This mixture was then sealed under vacuum and placed in an oven maintained at about $185^{\circ} \mathrm{C}$ for $3-4$ days. The tube was then cooled and opened, and the content was dissolved in acetone. The insoluble material was filtered off, the filtrate evaporated to dryness under vacuum, and the residue sublimed under reduced pressure $\left(300 \mathrm{mTorr} / 220^{\circ} \mathrm{C}\right)$. The product was crystallized from a mixture of $\mathrm{CH}_{2} \mathrm{Cl}_{2}$ and hexane, to give $\mathbf{3}$ as colorless needle-like crystals (169 mg, $0.25 \mathrm{mmol}, 38 \%$ )

Spectral data of 3: MS (EI, $\left.{ }^{192} \mathrm{Os}\right): \mathrm{m} / \mathrm{z}: 674\left[\mathrm{M}^{+}\right], 618\left[\mathrm{M}^{+}-2 \mathrm{CO}\right]$. IR $\left(\mathrm{CH}_{2} \mathrm{Cl}_{2}\right): v=2054$ (s), $1986 \mathrm{~cm}^{-1}$ (s) (CO); ${ }^{1} \mathrm{H}$ NMR (400 MHz, $\mathrm{CDCl}_{3}$, $298 \mathrm{~K}): \delta=9.01\left(\mathrm{dd}, J_{\mathrm{H} . \mathrm{H}}=6.7,0.8 \mathrm{~Hz} ; \mathrm{H}_{\mathrm{py}}\right), 8.32\left(\mathrm{dd}, J_{\mathrm{H} . \mathrm{H}}=7.6,0.8 \mathrm{~Hz}\right.$; $\left.\mathrm{H}_{\mathrm{py}}\right), 8.17\left(\mathrm{ddd}, J_{\mathrm{H}, \mathrm{H}}=7.6,6.7,0.8 \mathrm{~Hz} ; \mathrm{H}_{\mathrm{py}}\right), 7.51 \mathrm{ppm}\left(\mathrm{ddd}, J_{\mathrm{H}, \mathrm{H}}=6.7,7.6\right.$, $\left.0.8 \mathrm{~Hz} ; \mathrm{H}_{\mathrm{py}}\right)$; elemental analysis calcd $(\%)$ for $\mathrm{C}_{18} \mathrm{H}_{8} \mathrm{~F}_{6} \mathrm{~N}_{8} \mathrm{O}_{2} \mathrm{Os}$ : C 32.15, N 16.66, H 1.20; found: C 32.02, N 16.87, H 1.53.

Measurements: Single-crystal X-ray diffraction data were measured on a Nonius Kappa or a Bruker SMART CCD diffractometer using $\mathrm{Mo}_{\mathrm{K} \alpha}$ radiation $(\lambda=0.71073 \AA)$. Data collection was performed by using the SMART program. Cell refinement and data reduction were made with the SAINT program. The structure was determined using the SHELXTL/PC program and refined by using the full-matrix least-squares method. All non-hydrogen atoms were refined anisotropically, whereas hydrogen atoms were placed at the calculated positions and included in the final stage of the refinements with fixed positional parameters. The crystallographic refinement parameters of complexes $\mathbf{1}$ and $\mathbf{2}$ are summarized in Table 1, and the selective bond lengths and angles of these complexes are listed in Table 2 and Table 3, respectively.

CCDC-246508 (1) and CCDC-246509 (2) contain the supplementary crystallographic data for this paper. These data can be obtained free of charge via www.ccdc.cam.ac.uk/conts/retrieving.html (or from the Cambridge Crystallographic Data Centre, 12, Union Road, Cambridge CB2 1EZ, UK; fax: (+44)1223-336-033; or deposit@ccdc.cam.ac.uk).

Steady-state absorption and emission spectra were recorded on a Hitachi (U-3310) spectrophotometer and an Edinburgh (FS920) fluorimeter, re- spectively. Quinine sulfate with an emission yield of $\Phi \sim 0.57$ in $0.1 \mathrm{M}$ $\mathrm{H}_{2} \mathrm{SO}_{4}$ served as the standard to calculate the emission quantum yield. Nanosecond lifetime studies were performed by using an Edinburgh FL 900 photon-counting system with a hydrogen-filled/or a nitrogen lamp as the excitation source. Data were analyzed by using the nonlinear leastsquares procedure in combination with an iterative convolution method. The emission decays were measured as the sum of the exponential functions, which allows partial removal of the instrument time broadening and consequently gives a temporal resolution of about $200 \mathrm{ps}$. The longlived $(>10 \mu \mathrm{s})$ phosphorescence spectra were measured by an ultrasensitive detection system coupled with a laser excitation source. Briefly, an Nd:YAG (355 nm, 8 ns, Continuum Surelite II) -pumped optical parametric oscillator coupled with a second harmonic device served as a tunable excitation source. The resulting emission was detected with an intensified charge-coupled detector (ICCD, Princeton Instrument, Model 576G/1).

Computational methodology: Calculations on the electronic ground states of complexes $\mathbf{1}$ and $\mathbf{2}$ were carried out using B3LYP density functional theory. ${ }^{[27,28]}$ "Double- $\zeta$ " quality basis sets were employed for the ligands $\left(6-31 G^{*}\right)$ and the osmium atom (LANL2DZ). A relativistic effective core potential $(\mathrm{ECP})$ on osmium ${ }^{[29]}$ replaced the inner core electrons leaving the outer core $\left(5 s^{2} 5 p^{6}\right)$ electrons and the $5 d^{6}$ valence electrons of $\mathrm{Os}^{\mathrm{II}}$. The ground-state geometry was adapted from the truncated X-ray data without further optimization. For this geometry, a time-dependent DFT (TDDFT) calculation ${ }^{[30]}$ using the B3LYP functional was performed. Typically, the lowest 10 triplet and 10 singlet roots of the nonhermitian eigenvalue equations were obtained to determine the vertical excitation energies. Oscillator strengths were deduced from the dipole transition matrix elements (for singlet states only). The ground-state B3LYP and excited-state TDDFT calculations were carried out using Gaussian98. ${ }^{[31]}$

\section{Acknowledgement}

We thank the National Science Council of Taiwan for generous financial support (NSC 91-2119 M-002-016 and NSC 91-2113 M-007-006).

[1] a) M. Gratzel, Nature 2001, 414, 338; b) V. Balzani, A. Juris, Coord. Chem. Rev. 2001, 211, 97; c) P. A. Anderson, F. R. Keene, T. J. Meyer, J. A. Moss, G. F. Strouse, J. A. Treadway, J. Chem. Soc., Dalton Trans. 2002, 3820.

[2] K. A. King, P. J. Spellane, R. J. Watts, J. Am. Chem. Soc. 1985, 107, 1431.

[3] a) R. Gao, D. G. Ho, B. Hernandez, M. Selke, D. Murphy, P. I. Djurovich, M. E. Thompson, J. Am. Chem. Soc. 2002, 124, 14828; b) M. C. DeRosa, P. J. Mosher, G. P. A. Yap, K.-S. Focsaneanu, R. J. Crutchley, C. E. B. Evans, Inorg. Chem. 2003, 42, 4864.

[4] a) C.-M. Che, Y.-J. Hou, M. C. W. Chan, J. Guo, Y. Liu, Y. Wang, J. Mater. Chem. 2003, 13, 1362; b) B. W. D'Andrade, J. Brooks, V. Adamovich, M. E. Thompson, S. R. Forrest, Adv. Mater. 2002, 14, 1032; c) J. Brooks, Y. Babayan, S. Lamansky, P. I. Djurovich, I. Tsyba, R. Bau, M. E. Thompson, Inorg. Chem. 2002, 41, 3055; d) W. Lu, B.-X. Mi, M. C. W. Chan, Z. Hui, C.-M. Che, N. Zhu, S.-T. Lee, J. Am. Chem. Soc. 2004, 126, 4958; e) J. Kavitha, S.-Y. Chang, Y. Chi, J.-K. Yu, Y.-H. Hu, P.-T. Chou, S.-M. Peng, G.-H. Lee, Y.-T. Tao, C.-H. Chien, A. J. Carty, Adv. Funct. Mater. 2004, in press.

[5] a) P. A. Bonnardel, R. V. Parish, R. G. Pritchard, J. Chem. Soc., Dalton Trans. 1996, 3185; b) Y. Fuchita, H. Ieda, Y. Tsunemune, J. Kinoshita-Nagaoka, H. Kawano, J. Chem. Soc., Dalton Trans. 1998, 791.

[6] a) V. W.-W. Yam, Chem. Commun. 2001, 789; b) D. R. Striplin, G. A. Crosby, Coord. Chem. Rev. 2001, 211, 163; c) S. Ranjan, S.-Y. Lin, K.-C. Hwang, Y. Chi, W.-L. Ching, C.-S. Liu, Y.-T. Tao, C.-H. Chien, S.-M. Peng, G.-H. Lee, Inorg. Chem. 2003, 42, 1248; d) F. Li, M. Zhang, J. Feng, G. Cheng, Z. Wu, Y. Ma, S. Liu, J. Sheng, S. T. Lee, Appl. Phys. Lett. 2003, 83, 365.

[7] a) B. Carlson, G. D. Phelan, W. Kaminsky, L. Dalton, X. Z. Jiang, S. Liu, A. K.-Y. Jen, J. Am. Chem. Soc. 2002, 124, 14162; b) S. Bern- 
hard, X. Gao, G. G. Malliaras, H. D. Abruna, Adv. Mater. 2002, 14, 433; c) Y. Ma, H. Zhang, J. Shen, C. Che, Synth. Met. 1998, 94, 245.

[8] a) A. Tsuboyama, H. Iwawaki, M. Furugori, T. Mukaide, J. Kamatani, S. Igawa, T. Moriyama, S. Miura, T. Takiguchi, S. Okada, M. Hoshino, K. Ueno, J. Am. Chem. Soc. 2003, 125, 12971; b) J. C. Ostrowski, M. R. Robinson, A. J. Heeger, G. C. Bazan, Chem. Commun. 2002, 784; c) X. Gong, J. C. Ostrowski, G. C. Bazan, D. Moses, A. J. Heeger, M. S. Liu, A. K.-Y. Jen, Adv. Mater. 2003, 15, 45; d) V. V. Grushin, N. Herron, D. D. LeCloux, W. J. Marshall, V. A. Petrov, Y. Wang, Chem. Commun. 2001, 1494; e) Y.-H. Song, S.-J. Yeh, C.-T. Chen, Y. Chi, C.-S. Liu, J.-K. Yu, Y.-H. Hu, P.-T. Chou, S.-M. Peng, G.-H. Lee, Adv. Funct. Mater. 2004, in press.

[9] a) F. Barigelletti, D. Sandrini, M. Maestri, V. Balzani, A. Von Zelewsky, L. Chassot, P. Jolliet, U. Maeder, Inorg. Chem. 1988, 27, 3644; b) M. Gianini, A. Forster, P. Haag, A. von Zelewsky, H. StoeckliEvans, Inorg. Chem. 1996, 35, 4889.

[10] M. A. Baldo, M. E. Thompson, S. R. Forrest, Pure Appl. Chem. 1999, 71, 2095.

[11] a) M. K. Nazeeruddin, R. Humphry-Baker, D. Berner, S. Rivier, L. Zuppiroli, M. Graetzel, J. Am. Chem. Soc. 2003, 125, 8790; b) S. Zalis, I. R. Farrell, A. Vlcek, J. Am. Chem. Soc. 2003, 125, 4580.

[12] a) W.-S. Huang, J. T. Lin, C.-H. Chien, Y.-T. Tao, S.-S. Sun, Y.-S. Wen, Chem. Mater. 2004, 16, 2480; b) S.-C. Lo, E. B. Namdas, P. L. Burn, I. D. W. Samuel, Macromolecules 2003, 36, 9721; c) X. Gong, J. C. Ostrowski, D. Moses, G. C. Bazan, A. J. Heeger, Adv. Funct. Mater. 2003, 13, 439; d) R. C. Kwong, M. R. Nugent, L. Michalski, T. Ngo, K. Rajan, Y.-J. Tung, M. S. Weaver, T. X. Zhou, M. Hack, M. E. Thompson, S. R. Forrest, J. J. Brown, Appl. Phys. Lett. 2002, 81, 162; e) C. Adachi, R. Kwong, S. R. Forrest, Org. Electron. 2001, $2,37$.

[13] E. M. Kober, J. V. Caspar, R. S. Lumpkin, T. J. Meyer, J. Phys. Chem. 1986, 90, 3722

[14] a) Y.-Q. Fang, N. J. Taylor, G. S. Hanan, F. Loiseau, R. Passalacqua, S. Campagna, H. Nierengarten, A. Van Dorsselaer, J. Am. Chem. Soc. 2002, 124, 7912; b) N. H. Damrauer, J. K. McCusker, Inorg. Chem. 1999, 38, 4268

[15] a) S. Tokito, T. Iijima, Y. Suzuri, H. Kita, T. Tsuzuki, F. Sato, Appl. Phys. Lett. 2003, 83, 569; b) R. J. Holmes, S. R. Forrest, Y.-J. Tung, R. C. Kwong, J. J. Brown, S. Garon, M. E. Thompson, Appl. Phys. Lett. 2003, 82, 2422.

[16] a) E. C. Constable, P. J. Steel, Coord. Chem. Rev. 1989, 93, 205; b) C. J. Elsevier, J. Reedijk, P. H. Walton, M. D. Ward, Dalton Trans. 2003, 1869.

[17] a) C.-C. Cheng, W.-S. Yu, P.-T. Chou, S.-M. Peng, G.-H. Lee, P.-C. Wu, Y.-H. Song, Y. Chi, Chem. Commun. 2003, 2628; b) P.-C. Wu, J.-K. Yu, Y.-H. Song, Y. Chi, P.-T. Chou, S.-M. Peng, G.-H. Lee, Organometallics 2003, 22, 4938.
[18] a) E. C. Constable, P. R. Raithy, D. N. Smit, Polyhedron 1989, 8, 367; b) K. D. Demadis, T. J. Meyer, P. S. White, Inorg. Chem. 1998, 37, 3610 .

[19] B. P. Sullivan, J. Phys. Chem. 1989, 93, 24

[20] a) M. G. Colombo, A. Hauser, H. U. Gudel, Top. Curr. Chem. 1994, 171, 143; b) D. R. Striplin, G. A. Crosby, Coord. Chem. Rev. 2001, 211, 163; c) A. Vogler, H. Kunkely, Coord. Chem. Rev. 2000, 200202, 991.

[21] For a recent relevant paper, see: A. Morimoto, L. Biczók, T. Yatsuhashi, T. Shimada, S. Baba, H. Tachibana, D. A. Tryk, H. Inoue, $J$. Phys. Chem. A. 2002, 106, 10089.

[22] a) A. Vogler, H. Kunkely, Top. Curr. Chem. 2001, 213, 143; b) M. M. Glezen, A. J. Lees, J. Am. Chem. Soc. 1988, 110, 3892.

[23] P. J. Hay, J. Phys. Chem. A 2002, 106, 1634.

[24] N. J. Turro, Modern Molecular Photochemistry, 1991, University Science Books, Mill Valley, Califorina, p. 170.

[25] a) A. B. Tamayo, B. D. Alleyne, P. I. Djurovich, S. Lamansky, I. Tsyba, N. N. Ho, R. Bau, M. E. Thompson, J. Am. Chem. Soc. 2003, 125, 7377; b) T. Karatsu, T. Nakamura, S. Yagai, A. Kitamura, K Yamaguchi, Y. Matsushima, T. Iwata, Y. Hori, T. Hagiwara, Chem. Lett. 2003, 32, 886.

[26] a) S. Kubota, M. Uda, T. Nakagawa, J. Heterocycl. Chem. 1975, 12, 855 ; b) K. Funabiki, N. Noma, G. Kuzuya, M. Matsui, K. Shibata, J. Chem. Res. (M) 1999, 1301.

[27] C. Lee, W. Yang, R. G. Parr, Phys. Rev. B 1988, 37, 785.

[28] A. D. Becke, J. Chem. Phys. 1993, 98, 5648.

[29] P. J. Hay, W. R. Wadt, J. Chem. Phys. 1985, 82, 299.

[30] a) C. Jamorski, M. E. Casida, D. R. Salahub, J. Chem. Phys. 1996, 104, 5134; b) M. Petersilka, U. J. Grossmann, E. K. U. Gross, Phys. Rev. Lett. 1996, 76, 1212; c) R. Bauernschmitt, R. Ahlrichs, F. H Hennrich, M. M. Kappes, J. Am. Chem. Soc. 1998, 120, 5052; d) M. E. Casida, J. Chem. Phys. 1998, 108, 4439; e) R. E. Stratmann, G. E. Scuseria, M. J. Frisch, J. Chem. Phys. 1998, 109, 8218.

[31] Gaussian 98 (Revision A.9), M. J. Frisch, G. W. Trucks, H. B. Schlegel, G. E. Scuseria, M. A. Robb, J. R. Cheeseman, V. G. Zakrzewski, J. A. Montgomery, R. E. Stratmann, J. C. Burant, S. Dapprich, J. M. Millam, A. D. Daniels, K. N. Kudin, M. C. Strain, O. Farkas, J. Tomasi, V. Barone, M. Cossi, R. Cammi, B. Mennucci, C. Pomelli, C. Adamo, S. Clifford, J. Ochterski, G. A. Petersson, P. Y. Ayala, Q. Cui, K. Morokuma, D. K. Malick, A. D. Rabuck, K. Raghavachari, J. B. Foresman, J. Cioslowski, J. V. Ortiz, B. B. Stefanov, G. Liu, A. Liashenko, P. Piskorz, I. Komaromi, R. Gomperts, R. L. Martin, D. J. Fox, T. Keith, M. A. Al-Laham, C. Y. Peng, A. Nanayakkara, C. Gonzalez, M. Challacombe, P. M. W. Gill, B. G. Johnson, W. Chen, M. W. Wong, J. L. Andres, M. Head-Gordon, E. S. Replogle, J. A. Pople, Gaussian, Inc., Pittsburgh, PA, 1998.

Received: June 14, 2004 Published online: November 3, 2004 